\title{
Cold rolled 304 stainless steel and its interation with liquid Sn
}

\author{
Chuang-dong Zhang, Yan Zhao*, Jian-jun Guan, Rong-hua Li, Feng Liu, Ping Liang
}

School of Mechanical Engineering, Liaoning Shihua University, Fushun 113001, Liaoning, China

*E-mail: zhaoyan-a@163.com

doi: $10.20964 / 2019.09 .72$

Received: 6 May 2019 / Accepted: 15 July 2019 / Published: 5 August 2019

The effect of strain-induced $\alpha^{\prime}$-martensite transformation and subsequent solution treatment on the interaction between stainless steel and liquid metal Sn was investigated. Liquid metal corrosion and electrochemical corrosion behavior was evaluated. A cold rolling (CR) treatment was performed to induce different amounts of $\alpha^{\prime}$-martensite. The reduction ratio of $36 \%, 55 \%$, and $78 \%$ was used, and solution treatment (ST) was carried out. The phase structure of the stainless steels was examined by $\mathrm{XRD}$, and the morphology and composition of the compound were formed by SEM and EDX. The results show that the cold rolling deformation leads to a large amount of $\alpha$-martensite transformation, and the solution treatment causes some martensite return to austenite. The deformed stainless steel interacts with liquid $\mathrm{Sn}$, forming a $(\mathrm{Fe}, \mathrm{Cr}) \mathrm{Sn}_{2}$ phase compound layer. The amount of deformation increases, the fine needle-like compound gradually increases, while the compound of the lath-like morphology gradually decreases. After the solution treatment, the fine needle-like compound returns to the lath-like morphology. The cold rolling treatment induces the $\alpha^{\prime}$-martensitic transformation, resulting in a significant change in the growth the Fe-Sn compound. At the low deformations of 36\% and $55 \%$, the cold rolling is found to decrease the pitting potential, and deteriorates the electrochemical corrosion behavior of stainless steel. At the deformation of $78 \%$, the pitting corrosion resistance is increased, and the compound thickness expresses a small change.

Keywords: Cold rolling, Austenitic stainless steel, Strain induced martensite, Electrochemical corrosion, Liquid metal corrosion

\section{$\underline{\text { FULL TEXT }}$}

(C) 2019 The Authors. Published by ESG (www.electrochemsci.org). This article is an open access article distributed under the terms and conditions of the Creative Commons Attribution license (http://creativecommons.org/licenses/by/4.0/). 